\title{
Expansion due to alkali-silica reaction of ferronickel slag fine aggregate in OPC and blended cement mortars
}

\author{
Ashish Kumer Saha ${ }^{1}$, Prabir Kumar Sarker² \\ ${ }^{1} \mathrm{PhD}$ student, Department of Civil Engineering, Curtin University, GPO Box U1987, Perth, \\ WA 6845, Australia, Email: a.saha@postgrad.curtin.edu.au \\ ${ }^{2}$ Senior Lecturer, Department of Civil Engineering, Curtin University, GPO Box U1987, \\ Perth, WA 6845, Australia, Email: p.sarker@curtin.edu.au
}

\section{Abstract}

About 14 tonnes of granulated ferronickel slag (FNS) is produced as by-product in the production process of 1 tonne of ferronickel. The physical properties of FNS are suitable for its use as fine aggregates in concrete. This paper presents a study on the expansion due to alkalisilica reaction (ASR) of mortar bars containing different percentages of FNS aggregates originated from garnierite ore. Accelerated mortar bar test (AMBT) was performed to measure the expansion of the samples. FNS was found to be reactive in Portland cement mortar according to the AMBT results. Class F fly ash and ground granulated blast furnace slag (GGBFS) were used as the ASR mitigating measures of the FNS aggregate. Experimental results show that the use of GGBFS was unable to reduce expansion to the required level. However, the use of $30 \%$ class F fly ash as a supplementary cementitious material was found to be effective in reducing the 21-day ASR expansion below $0.3 \%$ required by the Australian Standard. Observations by scanning electron microscopy confirmed the effectiveness of fly ash in mitigation of the ASR products of FNS aggregates. 
Keywords: Alkali-silica reaction, fine aggregate, ferronickel slag, supplementary cementing material.

\section{Introduction}

Laterite, garnierite and pentlandite ores are the primary sources of nickel. The ore is smelted in an electric furnace or rotary kiln in order to produce ferronickel. The granular slag comes out as a by-product of the production process of ferronickel. The slag is classified into three types, depending on its cooling method such as slow-cooling granulated, wind granulated and water granulated [1]. The ore contains low grade nickel and it undergoes through three major stages such as pre-reduction, reductive smelting and ferronickel enrichment in the process of producing ferronickel. A large quantity of slag is produced in the process of ferronickel production. Safe disposal of the slag is considered as a major issue for the ferronickel plants worldwide [2]. Almost 14 tonnes of slag is generated per tonne of ferronickel production [3]. On the other hand, in order to prevent the rapid depletion of natural fine aggregates, the use of industrial by-products and recycled aggregates in concrete has been studied extensively for the past few decades. The Japan Industrial Standard (JIS) 5011-2 [4] has produced recommendations for using FNS as aggregates in concrete. Sato et al. [5] and Sakoi et al. [6] showed that replacing natural fine aggregate with air granulated FNS produced in Japan exhibited higher compressive strength and modulus of elasticity of concrete. Shoya et al. [7] and Sugita et al. [8] reported that 50\% replacement of aggregates by the FNS exhibited better durability properties as compared to the control specimens. The study evaluated the permeability, carbonation and drying shrinkage properties of concrete. Though slags produced in different smelters may appear similar physically, their chemical compositions can vary significantly depending on the source of the ore and the manufacturing process. It is also essential to investigate the potential of alkali-silica reaction (ASR) of an aggregate. This is 
because certain aggregates can cause expansion due to ASR depending on their chemical compositions. Deleterious ASR may result in large expansion causing concrete structures to crack.

Stanton [9] identified that concrete structure can suffer from the deleterious expansion due to ASR. Cole et al. [10] reported surface cracking and expansion of old dams in Australia suffering from ASR. The mechanism of ASR is complicated and there are differences in opinions among the researchers. According to Lee [11], the reactive silica in aggregate is depolymerised in a highly alkaline condition. Hydrolysis of the silica takes place in the presence of sodium and potassium hydroxides and an alkali silicate gel is formed. This gel absorbs a large quantity of water from the surroundings resulting in an expansion of its volume. This expansion of the alkali-silica gel causes micro-cracking inside the aggregate as well as at the interface between aggregate and cement paste [12]. Usually, aggregates with amorphous structure, lattice defects and large surface area are more susceptible to ASR expansion [13]. The crystalline structure of silica is stable and the amorphous silica is considered to be reactive [14]. The presence of calcium is also regarded as an important factor in ASR expansion. The calcium content of the binder has a significant influence on the expansion due to ASR. The ASR expansion increases with the rise of calcium content in the binder [15]. Chatterji [16] showed that the expansion could be reduced by leaching out of the $\mathrm{Ca}(\mathrm{OH})_{2}$ from concrete. It was also observed that the reactive silica did not cause any harmful expansion if there was no calcium available in the binder [17]. The presence of a higher percentage of calcite was also found to cause greater expansion of concrete [18]. Since ASR is a slow process, accelerated tests of mortar or concrete specimens are usually conducted to assess the alkali reactivity of an aggregate. Such accelerated tests are recommended in testing Standards and Codes. A correlation between the accelerated ASR test results and the actual ASR in concrete structures was shown by Carse and Dux [19]. 

and silica fume is usually considered as a mitigating measure against the ASR expansion of concrete. However, the effectiveness of an SCM in reducing the ASR depends of the type and dosage of the SCM, and the type of the reactive aggregate. The effectiveness of an SCM depends on its alkali content, with higher alkali content exhibiting higher expansion [20]. Shehata and Thomas [21], and Shafaatian et al. [22] showed that expansion of mortar specimens containing reactive aggregates was reduced by the use of fly ash as a partial replacement of cement. Fly ash can significantly reduce the alkalinity of pore solution resulting in a reduction of the ASR [23]. The addition of reactive aggregates in powder form with the binder can also reduce the ASR as the powder acts as a pozzolana and reduces the alkalinity of the pore solution [24]. Although ASR is being studied for the past few decades, the exact chemical reactions that cause the expansion and cracking of concrete remains in shadow. has been investigated in this study. This particular FNS is extracted by pyro-metallurgy from garnierite ore and cooled down by sea water. It has different chemical compositions than the FNS aggregates used in the studies available in literature. Our other study [25] investigates the utilisation of the ground FNS as a partial replacement of cement. Petrographic analysis of the FNS showed the existence of glass containing amorphous and cryptocrystalline silica that might cause ASR when used as aggregates in concrete. Therefore, a study on the potential ASR expansion of the aggregate is essential for its development as an alternative fine aggregate for concrete. Accelerated ASR tests were conducted on mortar specimens containing different percentages of FNS as a replacement of natural sand. Fly ash and GGBFS were used as partial replacements of cement and their effectiveness on the ASR expansion were studied. Microstructural analysis using scanning electron micrographs (SEM) and energy-dispersive Xray spectroscopy (EDS) was performed to obtain an insight into the ASR products and the 
100

101

102

103

104

105

106

107

108

109

110

111

112

\section{1}

resulting expansions observed for the mortar mixtures containing different percentages of the FNS and SCMs.

\section{Experimental work}

\subsection{Materials}

The materials used in this study were ordinary Portland cement (OPC), FNS, class F fly ash and GGBFS. The chemical compositions of these materials are given in Table 1. It can be seen that the main components of the FNS were $\mathrm{SiO}_{2}, \mathrm{MgO}$ and $\mathrm{Fe}_{2} \mathrm{O}_{3}$. The $\mathrm{CaO}$ content of the fly ash was very low $(0.6 \%)$ as compared to that of GGBFS (41.2\%). The $\mathrm{SiO}_{2}$ content of the fly ash (76.4\%) was much higher than that of GGBFS (32.5\%). Furthermore, $\mathrm{Na}_{2} \mathrm{O}$ content was less in fly ash $(0.19 \%)$ than in OPC $(0.29 \%)$ and GGBFS $(0.27 \%)$.

2 Table 1 Chemical compositions and loss on ignition (LOI) of OPC, FNS, fly ash and GGBFS (mass \%)

\begin{tabular}{|l|l|l|l|l|}
\hline Material & OPC & FNS & Fly ash & GGBFS \\
\hline $\mathrm{SiO}_{2}$ & 20.29 & 52.52 & 76.34 & 32.45 \\
\hline $\mathrm{Al}_{2} \mathrm{O}_{3}$ & 5.48 & 2.33 & 14.72 & 13.56 \\
\hline $\mathrm{Fe}_{2} \mathrm{O}_{3}$ & 2.85 & 10.80 & 3.69 & 0.82 \\
\hline $\mathrm{MgO}$ & 1.24 & 33.16 & 0.54 & 5.10 \\
\hline $\mathrm{SO}_{3}$ & 2.49 & 0.06 & 0.11 & 3.20 \\
\hline $\mathrm{CaO}$ & 63.11 & 0.27 & 0.60 & 41.22 \\
\hline $\mathrm{Na}_{2} \mathrm{O}$ & 0.29 & 0.12 & 0.19 & 0.27 \\
\hline $\mathrm{K}_{2} \mathrm{O}$ & 0.45 & 0.04 & 0.96 & 0.35 \\
\hline $\mathrm{Cr}_{2} \mathrm{O}_{3}$ & 0.02 & - & - & - \\
\hline $\mathrm{P}_{2} \mathrm{O}_{5}$ & 0.17 & 0.01 & 0.10 & 0.03 \\
\hline $\mathrm{SrO}^{\mathrm{TiO}}$ & 0.05 & - & - & - \\
\hline $\mathrm{Mn}_{2} \mathrm{O}_{3}$ & 0.27 & 0.04 & 0.61 & 0.49 \\
\hline $\mathrm{ZnO}^{2 O}$ & 0.04 & - & - & - \\
\hline $\mathrm{LOI}$ & 3.39 & 0.01 & 0.53 & 1.11 \\
\hline
\end{tabular}



the natural sand.
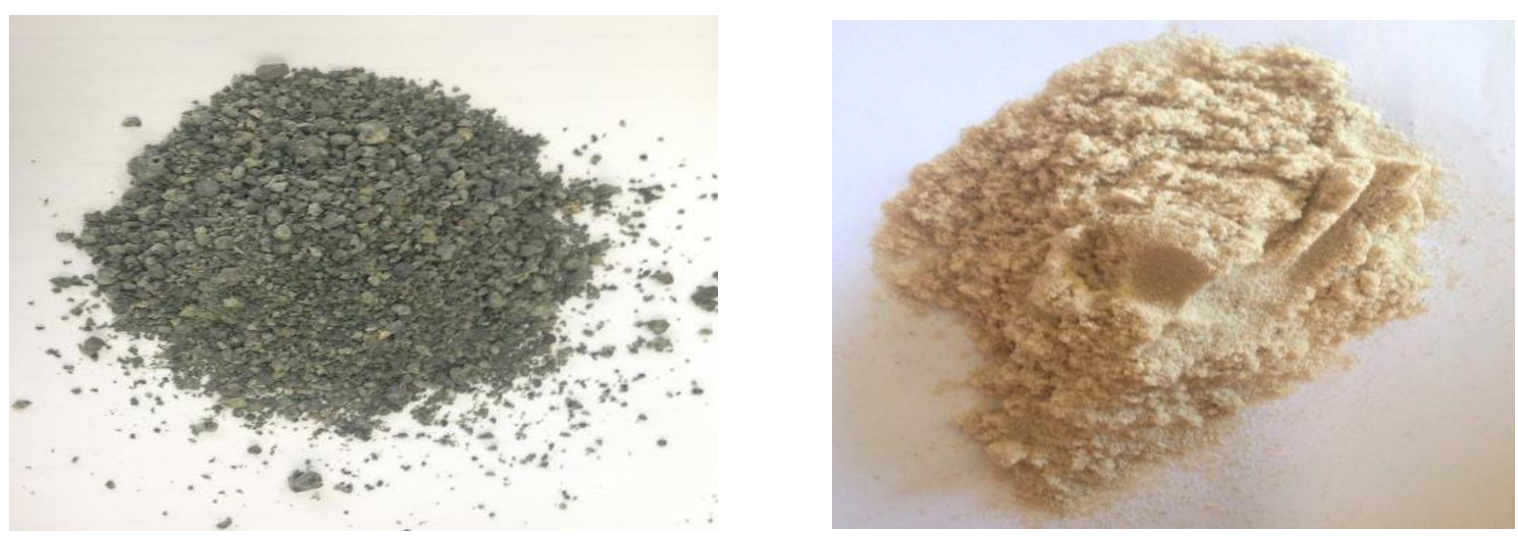

Figure 1. Granulated FNS (left) and natural sand (right).

Table 2 Physical properties of natural sand and FNS

\begin{tabular}{|l|l|l|}
\hline \multicolumn{1}{|c|}{ Property } & Sand & FNS \\
\hline SSD density $(\mathrm{kg} / \mathrm{m} 3)$ & 2.16 & 2.78 \\
\hline Apparent particle density $(\mathrm{kg} / \mathrm{m} 3)$ & 2.32 & 2.85 \\
\hline Fineness modulus & 1.95 & 4.07 \\
\hline
\end{tabular}

in Figure 2. The upper and lower limits of the grading requirements recommended by the Australian Standard AS 2758.1 [26] are also plotted in this figure. It can be seen that the particle size distributions for all the combinations are within the recommended limits of the AS 2758.1, except for $100 \%$ FNS, for which the distribution is slightly beyond the lower limit between 300 $\mu \mathrm{m}$ and $1.8 \mathrm{~mm}$ sizes. It is also evidenced that the grading curve becomes more smooth and 
continuous when the FNS and natural sand are mixed together. The most well-graded particle size distribution was obtained for the combination of 50\% FNS with $50 \%$ natural sand.

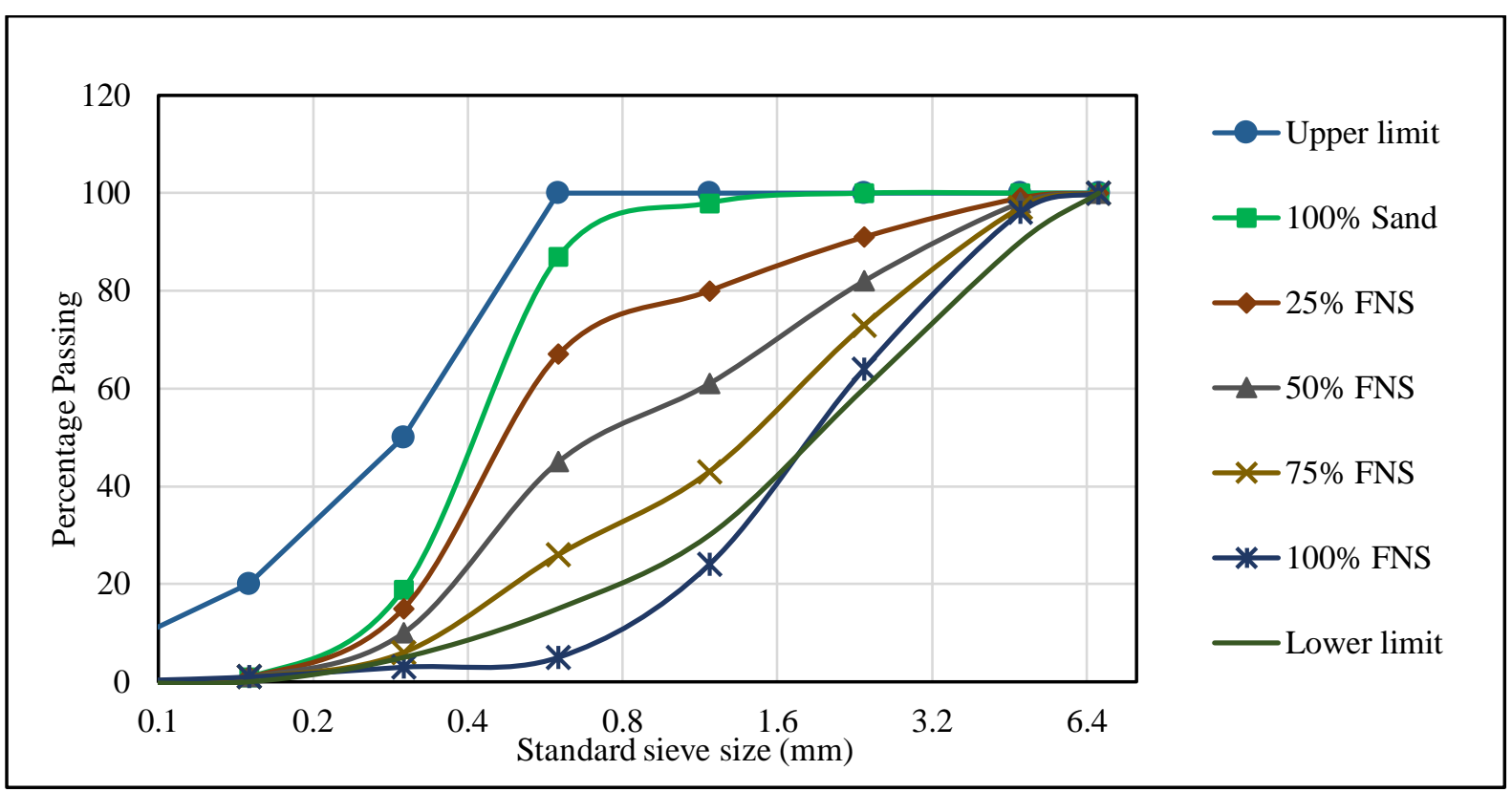

Figure 2. Particle size distributions of natural sand, FNS, their combinations, and the upper and lower limits of AS 2758.1 [26].

\subsection{Specimens and test methods}

Petrography and expansion tests are two most common tests used for identification of the alkali reactivity of aggregates. However, petrography test has the limitation of its efficiency in identifying the fine-grained reactive silica [27]. Accelerated mortar bar test (AMBT) was performed in this study, as it has been well accepted as a quick and efficient test to determine the alkali reactivity of fine aggregates. Since the aggregates slow reactivity might not come into reaction within a short period of 21 days, the test can be continued for a longer period of time [28]. Therefore, the test was extended up to 64 days in this study. The tests were conducted in accordance with the AS 1141.60.1 Standard [29]. The mortar bars were cast from mixtures with a water to binder ratio of 0.47 and binder to fine aggregate ratio of $1: 2.25$, as 
recommended in the Standard. The test specimens were made from mortar mixtures with FNS replacing natural sand by $25 \%, 50 \%, 75 \%$ and $100 \%$. Fly ash and GGFS were used as replacements of cement by $30 \%$ in order to study their effectiveness on mitigation of the ASR of FNS. A $30 \%$ cement replacement was selected as this percentage is considered to give a substantial reduction in the $\mathrm{CO}_{2}$ emission with a reasonable reduction in the strength of concrete [30]. The mixture proportions of the mortars are given in Table 3 . The binder of the mixtures of Series A was $100 \%$ OPC and those of Series B and C had 30\% fly ash and 30\% GGBFS respectively.

Table 3 Mixture proportions of mortars

\begin{tabular}{|l|l|l|l|l|l|l|}
\hline \multirow{2}{*}{ Mix ID } & \multicolumn{3}{|l|}{ Binder $\left(\mathbf{K g} / \mathbf{m}^{\mathbf{3}}\right)$} & \multicolumn{2}{l|}{ Fine aggregate $\left(\mathbf{K g} / \mathbf{m}^{3}\right)$} & \multirow{2}{*}{ W/C } \\
\cline { 2 - 6 } & OPC & FA & GGBFS & Sand & FNS & \\
\hline A1 & 602 & - & - & 1355 & - & \\
\hline A2 & 602 & - & - & 1015 & 338 & \\
\hline A3 & 602 & - & - & 678 & 678 & \\
\hline A4 & 602 & - & - & 338 & 1015 & \\
\hline A5 & 602 & - & - & - & 1355 & \multirow{2}{*}{0.47} \\
\hline B1 & 421 & 181 & - & 1355 & - & \\
\hline B2 & 421 & 181 & - & 1015 & 338 & \\
\hline B3 & 421 & 181 & - & 678 & 678 & \\
\hline B4 & 421 & 181 & - & 338 & 1015 & \\
\hline B5 & 421 & 181 & - & - & 1355 & \\
\hline C1 & 421 & - & 181 & 1355 & - & \\
\hline C2 & 421 & - & 181 & 1015 & 338 & \\
\hline C3 & 421 & - & 181 & 678 & 678 & \\
\hline C4 & 421 & - & 181 & 338 & 1015 & \\
\hline C5 & 421 & - & 181 & - & 1355 & \\
\hline
\end{tabular}

Mortar bar specimens of $25 \times 25 \times 285 \mathrm{~mm}$ were cast with gage studs inserted at the ends to measure the length change of the specimen. The specimens were cured at room temperature for 24 hours and then they were submerged in a water bath at $80{ }^{\circ} \mathrm{C}$ for one day, after which the initial measurement of the length was taken. Then, the samples were submerged in a bath of $1 \mathrm{~mol} / \mathrm{L} \mathrm{NaOH}$ solution. The first measurement of the change in length was 
conducted after three days of immersion using a digital length comparator with an accuracy of $0.001 \mathrm{~mm}$. The measurements were then continued at three days of intervals. A mortar bar specimen and measurement of its length change are shown in Figure 3. Measurements were taken within 10 seconds of removing samples from the solution.

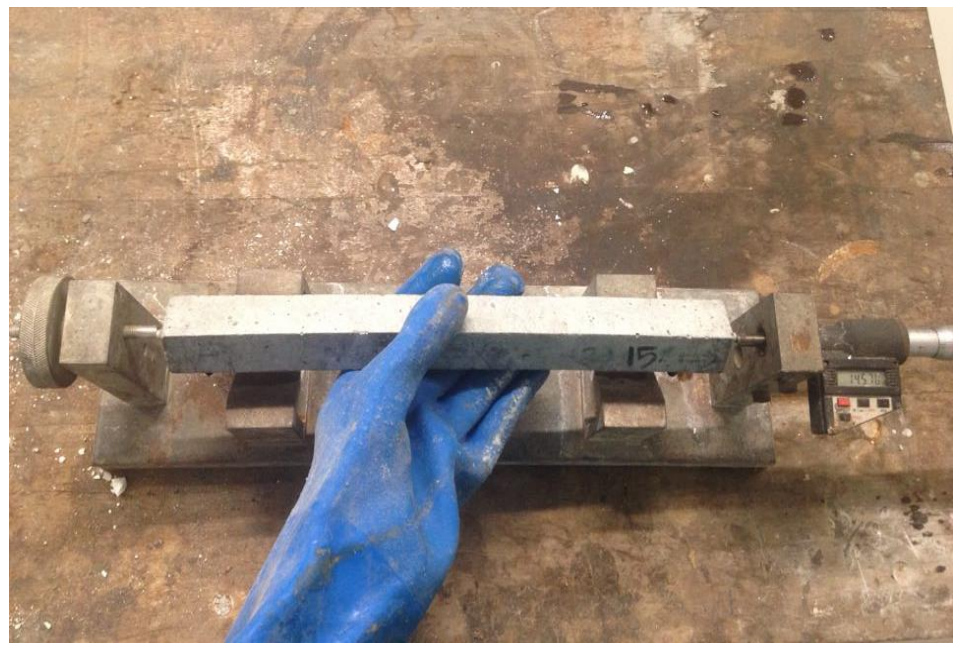

Figure 3. Length measurement of a mortar bar specimen.

\section{Results and Discussion}

\subsection{Mortar bar expansion}

The changes in the expansion of the mortar bars with increasing immersion period for the mixtures of $100 \%$ OPC (Series A) are shown in Figure 4. It can be seen that the expansion is relatively small in the specimen with $100 \%$ natural sand. However, expansion increased significantly with the inclusion of FNS in the mixture. The high expansion of the specimens is attributed to the presence of amorphous silica in the FNS. Petrographic examination showed that the FNS contained $44 \%$ amorphous and cryptocrystalline silica structures. Since the amorphous silica is reactive with the free alkali present in the binder matrix, the FNS showed high expansion due to the alkali-silica reaction. There was substantial increase of expansion in the specimens with $25 \%$ and $50 \%$ FNS. The expansion increased at relatively smaller rates 
with further increases in the percentage of FNS. The expansion of the specimen with $100 \%$ natural sand increased gradually over the period of immersion. On the other hand, the expansion of the specimens with $25 \%$ to $100 \%$ FNS increased at a high rate until 14 days and then continued to increase at slower rates until 64 days. The expansions after 64 days of immersion were $0.21 \%, 0.55 \%, 0.93 \%, 1.06 \%$ and $1.09 \%$ for the FNS contents of $0 \%, 25 \%$, $50 \%, 75 \%$ and $100 \%$ respectively. Thus, it can be seen that there are only small increases in the 64-day expansions by the increase in FNS above $50 \%$ up to $100 \%$. This trend is similar for the earlier periods of immersion.

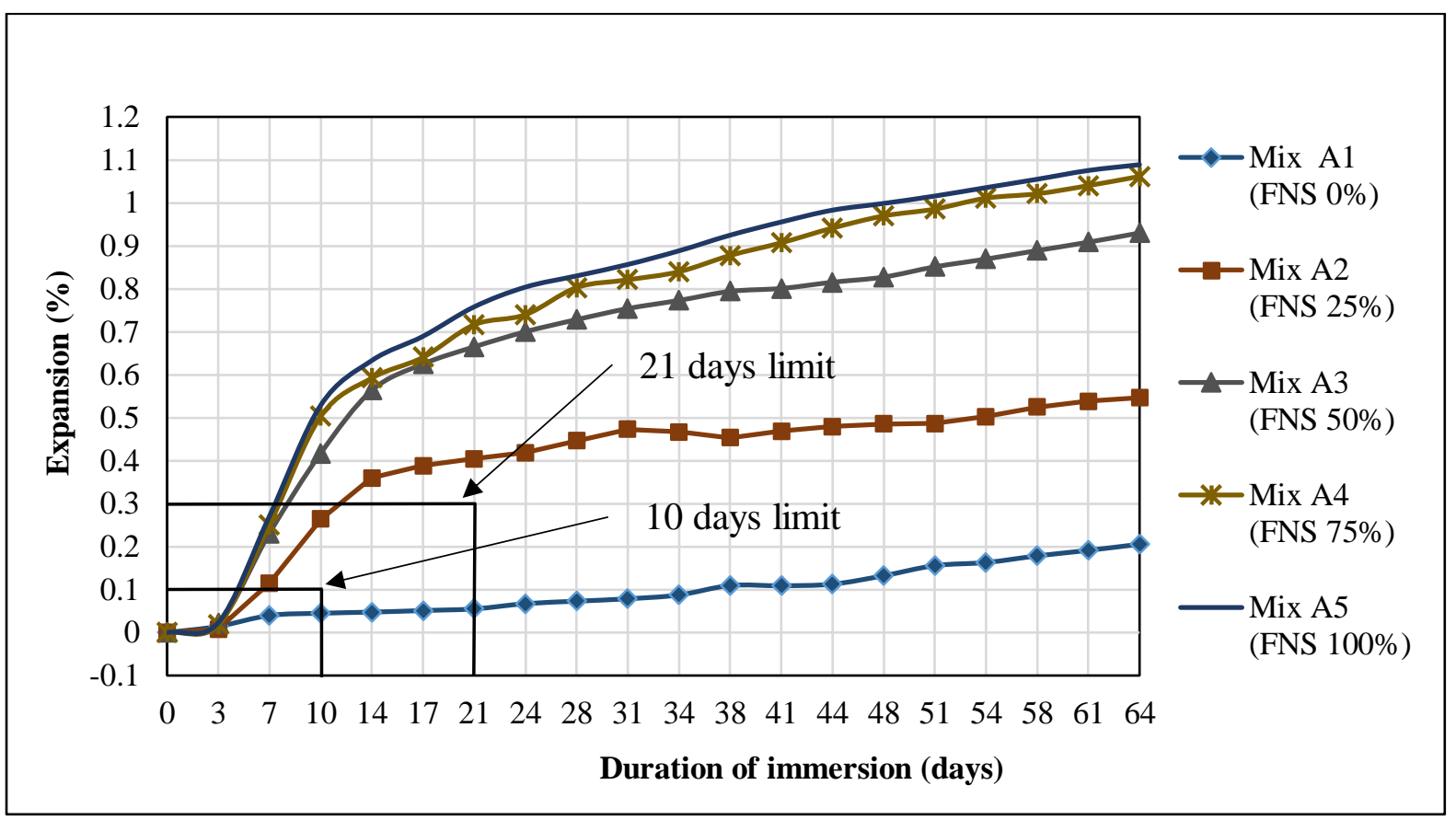

Figure 4. ASR expansions of mixtures of $100 \%$ OPC (Series A).

The reactivity classification according to the Australian Standard AS 1141.60.1 [29] is reproduced in Table 4 in order to compare with the AMBT results for different mixtures obtained in this study. According to this table, an aggregate should be classified as reactive if the expansion exceeds $0.30 \%$ within 21 days of immersion. Appropriate measures are required to reduce the expansion if reactive aggregates are to be used in concrete. The expansions of all the fifteen mixtures of this study after 21 days of immersion are collected in Table 5. Each mixture classified as reactive (R) or non-reactive (NR) by using the limits given in Table 4 are 
200

201

202

203

204

205

206

207

208

209

210

211

shown in Table 5. As shown in Fig. 4, the 14-day expansion of the specimen containing no FNS (Mix A1) is $0.05 \%$, which is much smaller than the $0.3 \%$ limit set by the Standard. Therefore, the natural sand is classified as non-reactive. On the other hand, the 14-day expansions of the specimens containing $25 \%$ to $100 \%$ FNS are higher than the $0.3 \%$ limit. Therefore, the FNS is classified as a reactive aggregate in accordance with AS 1141.60.1 [29]. According to the Australian Standard AS 2758.1 [26], some ASR mitigating measure is required for this FNS if it is to be used as an aggregate for concrete. Therefore, $30 \%$ fly ash and $30 \%$ GGBFS were used as SCMs, and their effects on the expansions of the mixtures containing $25 \%$ to $100 \%$ FNS were studied.

Table 4 Limits of AMBT expansion for reactivity classification as per AS1141.60.1 [29]

\begin{tabular}{|l|l|l|}
\hline \multicolumn{2}{|l|}{ Mean mortar bar expansion $(\mathrm{E}), \%$} & \multirow{2}{*}{ Aggregate reactivity classification } \\
\cline { 1 - 2 } Duration in $1 \mathrm{M} \mathrm{NaOH}$ at $80^{\circ} \mathrm{C}$ & \\
\hline 10 days & 21 days & Non-reactive \\
\hline- & $\mathrm{E}<0.10$ & Slowly reactive \\
\hline $\mathrm{E}<0.10$ & $0.10 \leq \mathrm{E}<0.30$ & Reactive \\
\hline $\mathrm{E} \geq 0.10$ & - & Reactive \\
\hline- & $0.30 \leq \mathrm{E}$ & \\
\hline
\end{tabular}

Table 5 Expansion of mortar bars after 21 days in $1 \mathrm{M} \mathrm{NaOH}$ solution at $80{ }^{\circ} \mathrm{C}$

\begin{tabular}{|l|l|l|l|l|l|}
\hline \multirow{2}{*}{ Binder Composition } & \multicolumn{4}{|l|}{ Percentage of FNS as fine aggregate (\%) } \\
\cline { 2 - 6 } & $\mathbf{0}$ & $\mathbf{2 5}$ & $\mathbf{5 0}$ & $\mathbf{7 5}$ & $\mathbf{1 0 0}$ \\
\hline $\begin{array}{l}\text { 100\% OPC (Series A) } \\
\text { reactive classification }\end{array}$ & 0.06 & 0.40 & 0.66 & 0.72 & 0.76 \\
$\mathrm{NR}$ & $\mathrm{R}$ & $\mathrm{R}$ & $\mathrm{R}$ & $\mathrm{R}$ \\
\hline $\begin{array}{l}30 \% \text { Fly ash + 70\% OPC (Series B) } \\
\text { reactive classification }\end{array}$ & 0.02 & 0.03 & 0.05 & 0.05 & 0.06 \\
& $\mathrm{NR}$ & $\mathrm{NR}$ & $\mathrm{NR}$ & $\mathrm{NR}$ & $\mathrm{NR}$ \\
\hline $\begin{array}{l}30 \% \text { GGBFS + 70\% OPC (Series C) } \\
\text { reactive classification }\end{array}$ & 0.04 & 0.34 & 0.63 & 0.69 & 0.72 \\
$\mathrm{NR}$ & $\mathrm{R}$ & $\mathrm{R}$ & $\mathrm{R}$ & $\mathrm{R}$ \\
\hline
\end{tabular}

$\mathrm{NB}: \mathrm{NR}=$ non reactive; $\mathrm{R}=$ reactive

The expansion results of the mixtures with $30 \%$ fly ash replacing cement (Series B) are presented in Figure 5. Slight initial shrinkage was observed in the specimens of 0 to $50 \%$ FNS. 
215 This is attributed to the initial autogenous shrinkage and low expansion by the use of fly ash 216 replacing $30 \%$ cement. It can be seen that the expansions of the mixtures containing $30 \%$ fly 217 ash are much lower than the values for the mixtures of $100 \%$ OPC. For example, the maximum 218 64-day expansion in this series is $0.09 \%$ for the mixture with $100 \%$ FNS. This value is much 219 smaller than the expansion (1.09\%) for the mixture with 100\% FNS and $100 \%$ OPC. This shows that $30 \%$ fly ash as cement replacement has significantly reduced the expansion due to 221 ASR in the mortar specimens containing $25 \%$ to $100 \%$ FNS. While the expansions of all the mixtures are seen to increase with increasing duration of immersion, the rates of increase are seen to be negligibly small after immersion for 64 days. As shown in Table 3, the expansions varied between $0.02 \%$ and $0.06 \%$ for $0 \%$ to $100 \%$ FNS. These values are much smaller than the $0.3 \%$ limit of the Australian Standard [29]. Therefore, the replacement of cement by 30\% class F fly ash can be considered as an effective ASR mitigating measure for concrete using FNS up to $100 \%$ replacement of natural sand.

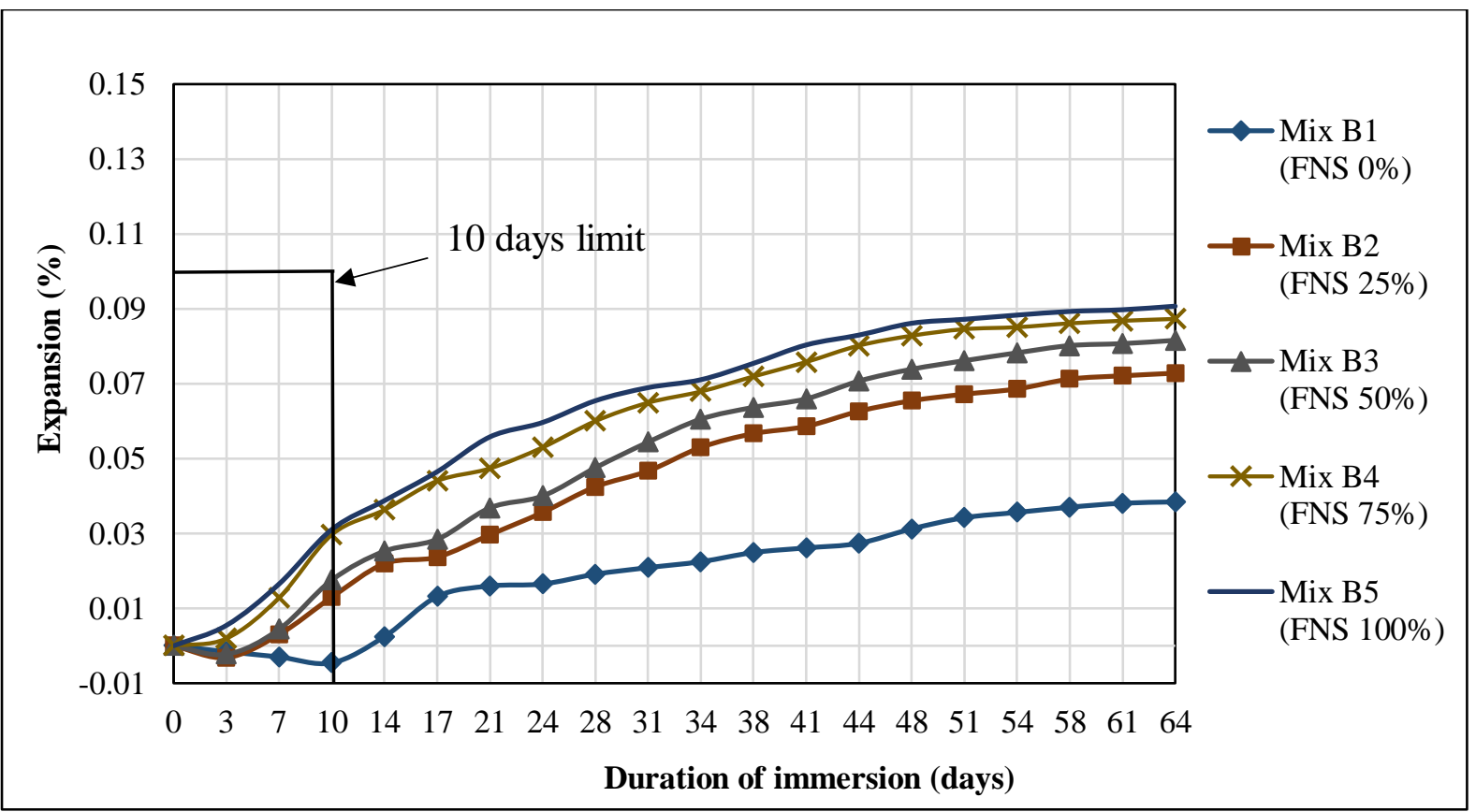

Figure 5. ASR expansions of the mixtures of $70 \%$ OPC and 30\% fly ash (Series B) 
232 (Series C) are shown in Figure 6. It can be observed that the expansions of the specimens of

this series are higher than those using fly ash as cement replacement. The higher expansions of

234 these mixtures are attributed to the higher $\mathrm{CaO}$ content of GGBFS (41\%) as compared to that of fly ash $(0.6 \%)$. The higher $\mathrm{CaO}$ increased the total alkali content of the binder as compared to the mixtures with fly ash. Thus, the expansions due to ASR are higher in the mixtures with GGBFS than those of the mixtures with fly ash. The specimens with FNS continued to expand for immersions beyond 21 days, and the expansion became almost stable after 64 days of immersion. The 64 -day expansion varied from $0.53 \%$ to $0.98 \%$ for the FNS content varying between $25 \%$ and $100 \%$. Similar to the mixtures of other two series, there has been very small increase in the expansion for the increase in the percentage of FNS beyond $50 \%$.

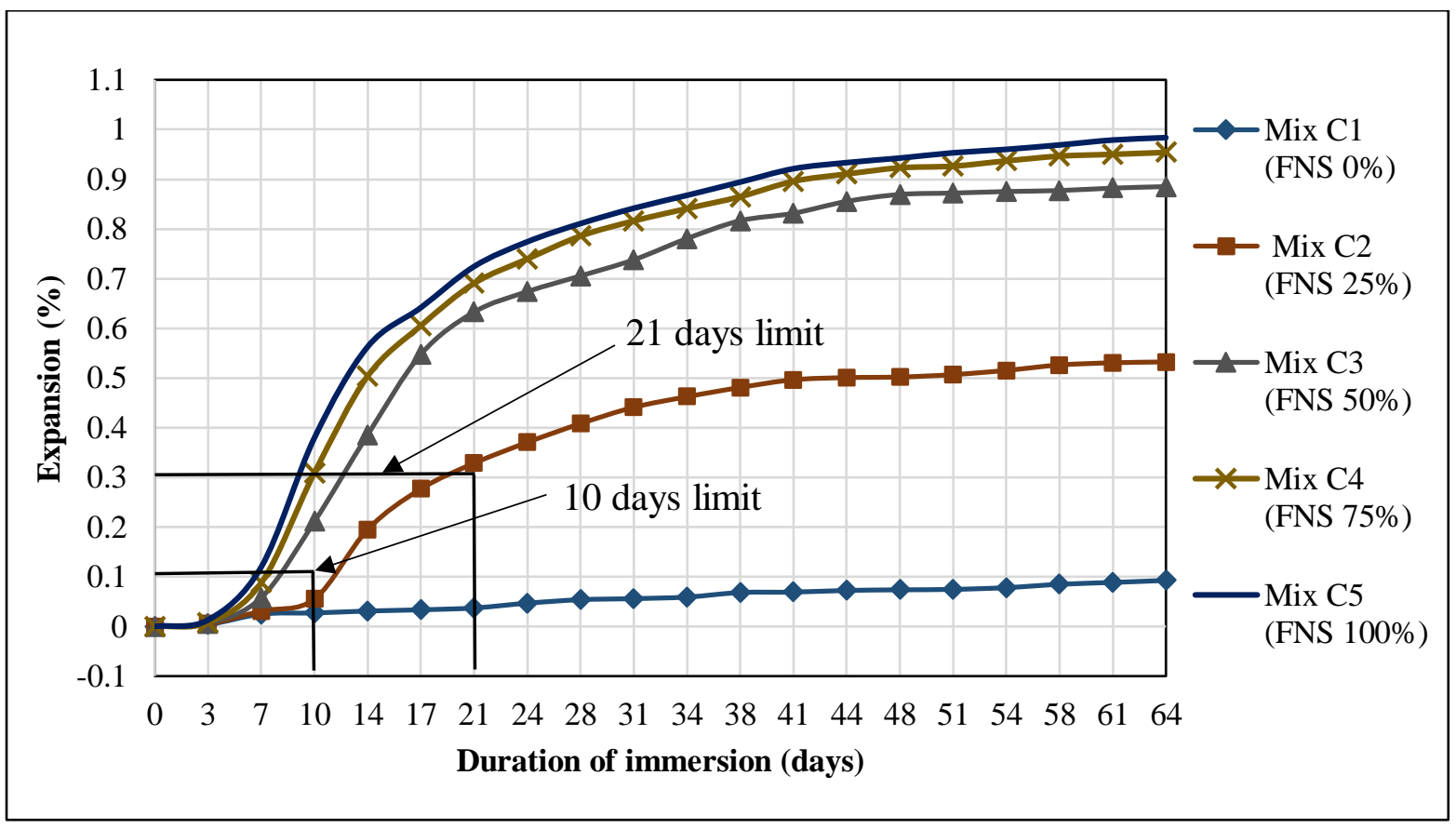

Figure 6. ASR expansions of mixtures with 70\% OPC and 30\% GGBFS (Series C)

The expansions of the specimens after 21 and 64 days of immersion are plotted against the percentage of FNS as replacement of natural sand in Figure 7. The $0.3 \%$ limit on the 
expansion after 21 days of immersion is also shown in this figure. It can be seen from the figure that the expansions of the specimen containing $30 \%$ fly ash are below this limit for the mixtures up to $100 \%$ FNS. Expansion of the specimen with $25 \%$ FNS and 30\% GGBFS just exceeded the limit of the Australian Standard [29] marginally and further increased with the increase of the percentage of FNS. However, the increase in expansion for the specimens of $75 \%$ and $100 \%$ FNS were very small as compared to that with $50 \%$ FNS. This trend is similar to the mixtures with $100 \%$ OPC, $30 \%$ fly ash and $30 \%$ GGBFS. The increase in the expansion for the FNS content beyond $50 \%$ is very small because there is less free alkali available for reaction with the additional FNS aggregates. Therefore, it can be concluded that $30 \%$ fly ash effectively reduced the expansion below the limit of the Australian Standard when FNS was used as a replacement of natural sand by up to $100 \%$. However, the reduction of expansion by $30 \%$ GGBFS as cement replacement for FNS content of $25 \%$ and above was not enough to meet the limit of the Australian Standard.

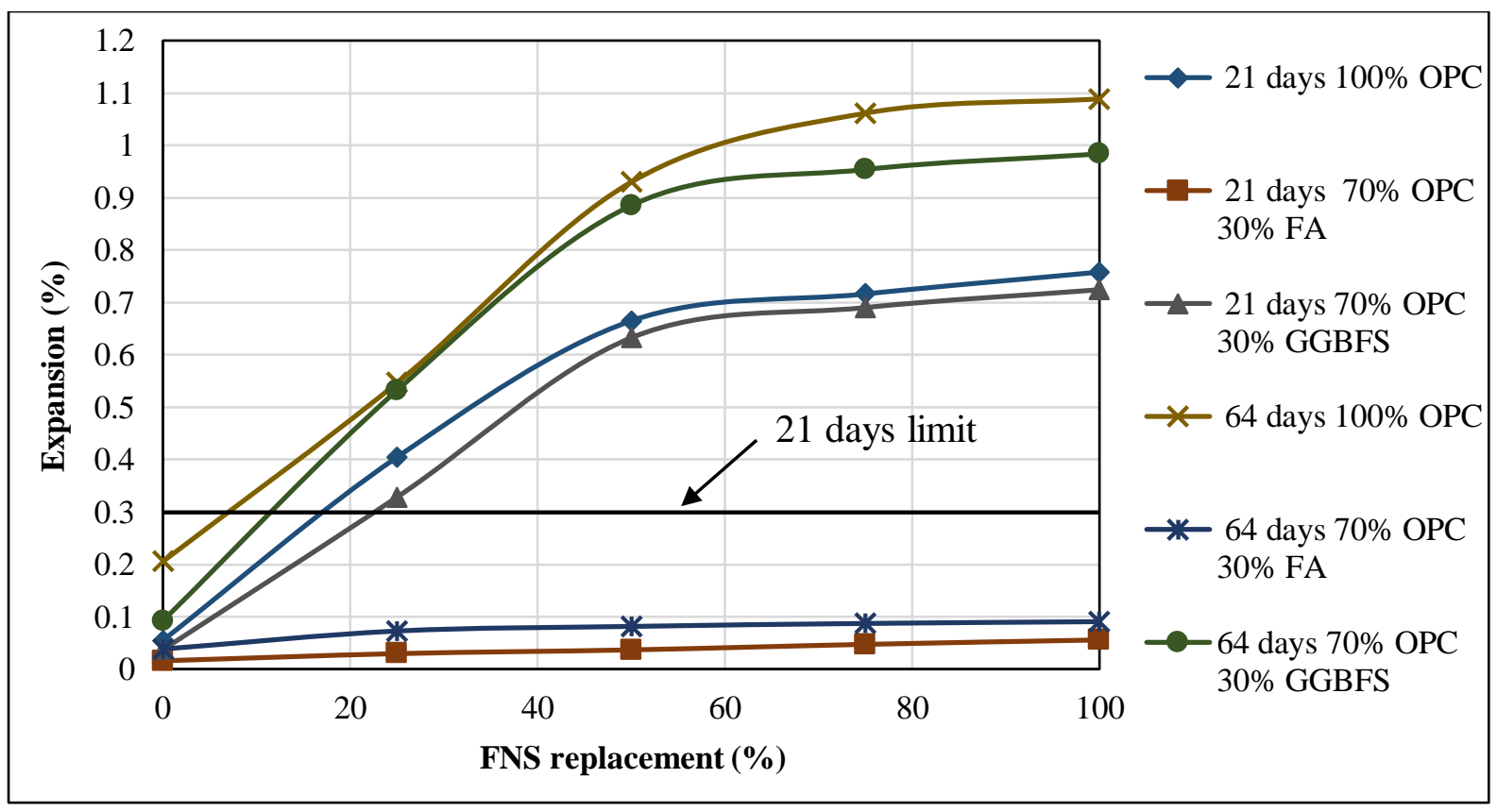




\subsection{Study of the microstructure by SEM and EDS}

266

The specimens containing 100\% FNS aggregates from the 3 series of mixtures were

267

268

269

270

271

272

273

274

275

276
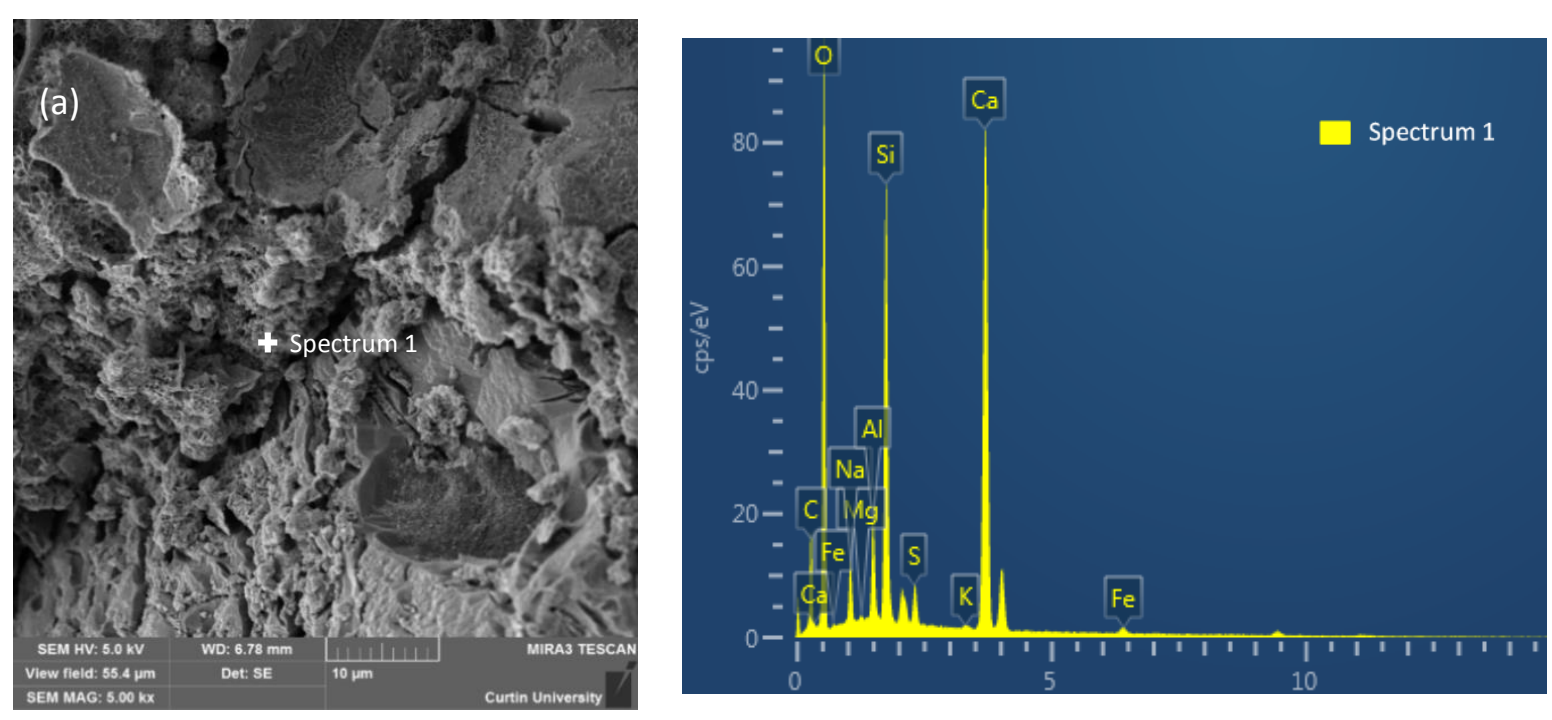

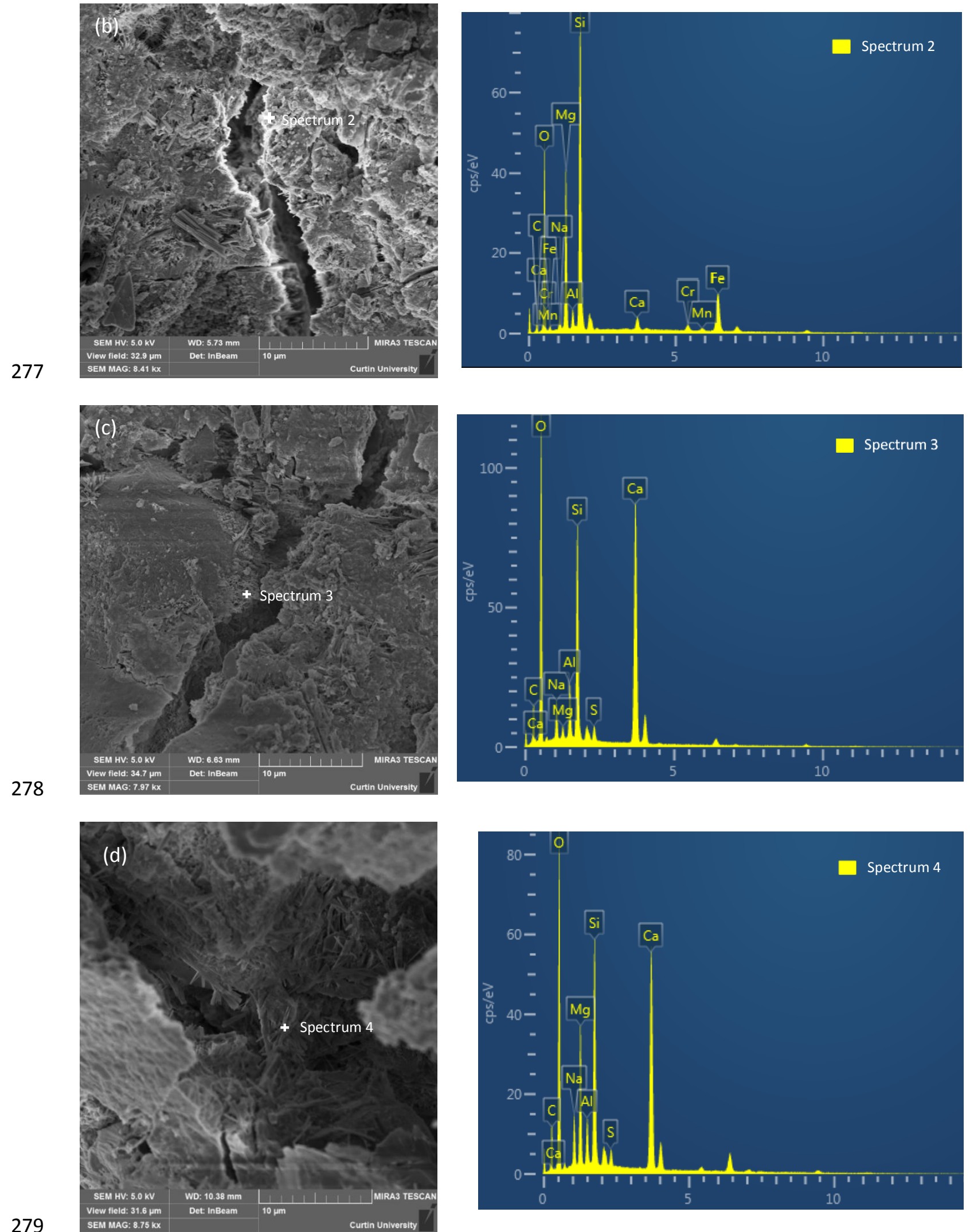

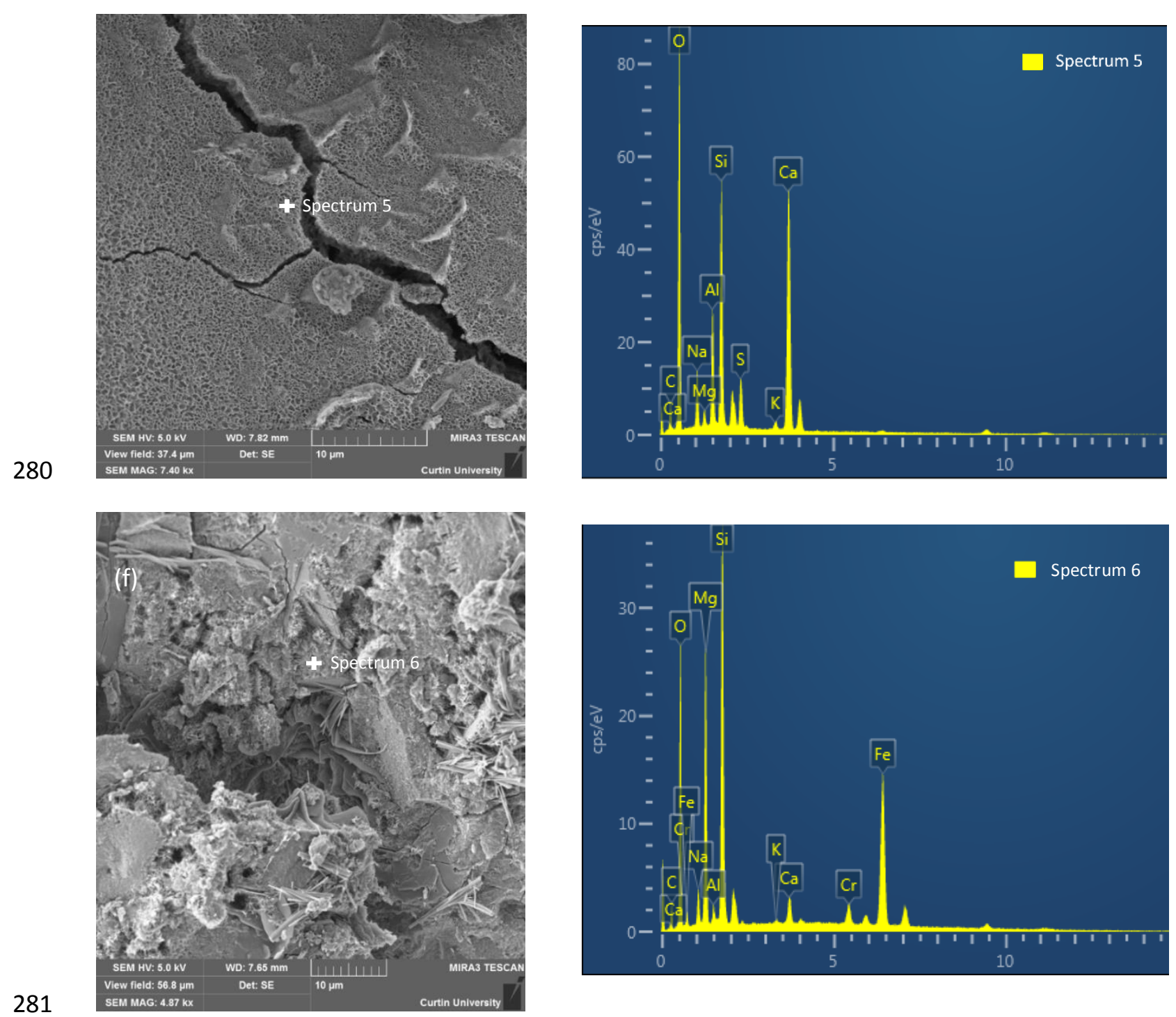

Figure 8. SEM and EDS data of: (a) Mix A1, (b) Mix A5, (c) Mix B1, (d) Mix B5, (e) Mix

OPC and 30\% GGBFS (Fig. 8f) exhibited formation of foil-like crystals and rosette-like accumulation on the aggregate surface and in the micro-cracks. The EDS data of the product in these specimens show that they have high silica content. As a result, they have low $\mathrm{Ca} / \mathrm{Si}$ ratios as compared to the other specimens. The $\mathrm{Ca} / \mathrm{Si}$ ratio of the specimens with $100 \% \mathrm{OPC}$ (A5) and 30\% GGBFS (C5) are 1.64 and 1.85 respectively. On the other hand, specimens of the mixtures $\mathrm{A} 1, \mathrm{~B} 1, \mathrm{~B} 5$ and $\mathrm{C} 1$ have $\mathrm{Ca} / \mathrm{Si}$ ratios of $2.33,2.57,2.59$ and 2.44 respectively. The lower $\mathrm{Ca} / \mathrm{Si}$ ratios of specimens $\mathrm{A} 5$ and $\mathrm{C} 5$ indicate that the silica of the FNS aggregates 
reacted with alkaline pore solution to make the ratio lower. Since there was no FNS aggregate in the mixtures $\mathrm{A} 1, \mathrm{~B} 1$ and $\mathrm{C} 1$, there was no contribution of silica from the aggregates to the reaction product. Thus, the $\mathrm{Ca} / \mathrm{Si}$ ratios of these samples were high. Since the specimen B5 contained $30 \%$ fly ash as cement replacement, there was less Portlandite available for the FNS aggregate to react with. For this reason, the $\mathrm{Ca} / \mathrm{Si}$ ratio was high for this specimen. Thus, ASR expansion of the specimens using $30 \%$ fly ash as supplementary cementitious material was low even though FNS was used as $100 \%$ fine aggregate in these specimens.

\section{Conclusion}

The reactivity of a proprietary ferronickel slag aggregate in cement mortar was studied by using the accelerated mortar bar test. The test consisted of periodic measurement of the length change of mortar specimens while immersed in $1 \mathrm{M} \mathrm{NaOH}$ solution at $80{ }^{\circ} \mathrm{C}$. The FNS aggregate was classified as reactive according to the Australian Standard AS 1141.60.1. Uses of class F fly ash and GGBFS as supplementary cementitious materials were investigated as the ASR mitigating measure of the FNS. It was found from the AMBT results that $30 \%$ fly ash reduced the 21-day expansion of mortar bars containing up to $100 \%$ FNS to below $0.3 \%$ limit set by the Australian Standard. The expansions of the other specimens containing OPC alone or with $30 \%$ GGBFS in the binder and FNS content of $25 \%$ or more were above this limit. The expansions of these specimens increased significantly for continued immersion up to 64 days. The expansions of the specimens with $30 \%$ fly ash and up to $100 \%$ FNS remained below $0.3 \%$ for 64 days of immersion. The SEM photographs and EDS data showed the presence of ASR products on the surface of FNS aggregates in the specimens except those using $30 \%$ fly ash. Thus, $30 \%$ fly ash as a supplementary cementitious material was found as an effective measure for mitigating the ASR expansion of the ferronickel slag aggregate up to $100 \%$ replacement of natural sand. 


\section{Acknowledgement}

This research was funded and supported by SLN, New Caledonia. The authors gratefully acknowledge the contribution and continuous support from SLN through its research department and its consultant, Mr. D.J. Sassoon Gubbay.

\section{References}

[1] Japan Society of Civil Engineers. (1994). Guidelines for Construction Using Ferronickel Slag Fine Aggregate Concrete. (JSCE No. 24). Retrieved from http://www.jsce.or.jp on 20 May, 2015.

[2] Maragkos, I., Giannopoulou, I. P., \& Panias, D. (2009). Synthesis of ferronickel slagbased geopolymers. Minerals Engineering, 22(2), 196-203.

[3] Warner, A. E. M., Diaz, C. M., Dalvi, A. D., Mackey, P. J., \& Tarasov, A. V. (2006). JOM world nonferrous smelter survey, Part III: Nickel: Laterite. JOM, 58(4), 11-20.

[4] Japan Industrial Standard, (2003). Slag aggregate for concrete Part- 2: Ferronickel slag aggregate. JIS A 5011- 2. Retrieved from http://www.webstore.jsa.or.jp on May 25, 2015.

[5] Sato, T., Watanabe, K., Ota, A., Aba, M., \& Sakoi, Y. (2011). INFLUENCE OF EXCESSIVE BLEEDING ON FROST SUSCEPTIBILITY OF CONCRETE INCORPORATING FERRONICKEL SLAG AS AGGREGATES. OUR WORLD IN CONCRETE \& STRUCTURES, Singapore on 14-16 August 2011. Retrieved from http://www.cipremier.com on 15 April, 2015.

[6] Sakoi, Y., Aba, M., Tsukinaga, Y., and Nagataki, S. (2013). Properties of Concrete used in Ferronickel Slag Aggregate. Sustainable Construction Material and Technology, Kyoto, Japan. Retrieved from http://www.claisse.info on 28 April, 2015. 
[7] Shoya, M., Aba, M., Tsukinaga, Y., \& Tokuhashi, K. (2003). Frost resistance and air void system of self-compacting concrete incorporating slag as a fine aggregate. ACI Special Publication, 212.

[8] Sugita, M. S. S., Aba, Y. T. M., \& Tokuhasi, K. (1999). PROPERTIES OF SELFCOMPACTING CONCRETE WITH SLAG FINE AGGREGATES. In Exploiting Wastes in Concrete: Proceedings of the International Seminar Held at the University of Dundee, Scotland, UK on 7 September 1999 (p. 121). Thomas Telford.

[9] Stanton, T. E. (1942). Expansion of concrete through reaction between cement and aggregate. Transactions of The American Society of Civil Engineers,107(1), 54-84.

[10] Cole, W. F., Lancucki, C. J., \& Sandy, M. J. (1981). Products formed in an aged concrete. Cement and Concrete Research, 11(3), 443-454.

[11] Lee, N. (2005). Alkali-Silica Reactivity in Concrete. New Zealand: Branz Ltd.

[12] Ponce, J. M., \& Batic, O. R. (2006). Different manifestations of the alkali-silica reaction in concrete according to the reaction kinetics of the reactive aggregate. Cement and Concrete Research, 36(6), 1148-1156.

[13] Poole, A. B. (1992). Introduction to alkali-aggregate reaction in concrete. The AlkaliSilica Reaction in Concrete, Blackie, Glasgow and London, and Van NostrandReinhold, New York, 1-29.

[14] Lukschová, Š., Přikryl, R., \& Pertold, Z. (2009). Petrographic identification of alkalisilica reactive aggregates in concrete from 20th century bridges. Construction and building materials, 23(2), 734-741.

[15] Carrasquillo, R. L., \& Farbiarz, J. (1989). Alkali-aggregate reaction in concrete containing fly ash: Final report (No. FHWA/TX-90+ 450-3F).

[16] Chatterji, S. (1979). The role of $\mathrm{Ca}(\mathrm{OH}) 2$ in the breakdown of portland cement concrete due to alkali-silica reaction. Cement and concrete research, 9(2), 185-188. 
[17] Bleszynski, R. F., \& Thomas, M. D. (1998). Microstructural studies of alkali-silica reaction in fly ash concrete immersed in alkaline solutions. Advanced Cement Based Materials, 7(2), 66-78.

[18] García-Lodeiro, I., Palomo, A., \& Fernández-Jiménez, A. (2007). Alkali-aggregate reaction in activated fly ash systems. Cement and Concrete Research, 37(2), 175-183.

[19] Carse, A., \& Dux, P. F. (1990). Development of an accelerated test on concrete prisms to determine their potential for Alkali-Silica reaction. Cement and Concrete Research, 20(6), 869-874.

[20] Duchesne, J., \& Bérubé, M. A. (1994). The effectiveness of supplementary cementing materials in suppressing expansion due to ASR: another look at the reaction mechanisms part 2: pore solution chemistry. Cement and Concrete Research, 24(2), 221-230.

[21] Shehata, M. H., \& Thomas, M. D. (2000). The effect of fly ash composition on the expansion of concrete due to alkali-silica reaction. Cement and Concrete Research, 30(7), 1063-1072.

[22] Shafaatian, S. M., Akhavan, A., Maraghechi, H., \& Rajabipour, F. (2013). How does fly ash mitigate alkali-silica reaction (ASR) in accelerated mortar bar test (ASTM C1567)?. Cement and Concrete Composites, 37, 143-153.

[23] Nixon, P. J., Page, C. L., Bollinghaus, R., \& Canham, I. (1986). The effect of a PFA with a high total alkali content on pore solution composition and alkali silica reaction. Magazine of Concrete Research, 38(134), 30-35.

[24] Moisson, M., Cyr, M., Ringot, E., \& Carles-Gibergues, A. (2004, October). Efficiency of reactive aggregate powder in controlling the expansion of concrete affected by alkalisilica reaction (ASR). In 12th International Conference on AAR in concrete, Beijing, China (pp. 617-624). 
[25] Rahman, M.A. and Sarker, P. and Shaikh, F. (2015). Fresh and Early-Age Properties of Cement Pastes and Mortars Blended with Nickel Slag, in J. Sanjayan and K. SagoCrentsil (ed), 27th Biennial National Conference of the Concrete Institute of Australia in conjunction with the 69th RILEM Week, Aug 30 2015. Melbourne, Australia: Concrete Institute of Australia.

[26] Standards Australia. (1998). Aggregates and rock for engineering purposes (AS 2758.198). Retrieved from http://www.siaglobal.com on 12 May, 2015.

[27] Godart, B., de Rooij, M. R., \& Wood, J. G. (2013). Guide to Diagnosis and Appraisal of AAR Damage to Concrete in Structures. Springer Verlag.

[28] Thomas, M., Fournier, B., Folliard, K., Ideker, J., \& Shehata, M. (2006). Test methods for evaluating preventive measures for controlling expansion due to alkali-silica reaction in concrete. Cement and Concrete Research, 36(10), 1842-1856.

[29] Standards Australia. (2014). Method for sampling and testing aggregates, Potential alkali silica reactivity - Accelerated mortar bar method (AS 1141.60.1-14). Retrieved from http://www.siaglobal.com on 12 May, 2015.

[30] Nath, P., \& Sarker, P. K. (2013). Effect of mixture proportions on the drying shrinkage and permeation properties of high strength concrete containing class $\mathrm{F}$ fly ash. KSCE Journal of Civil Engineering, 17(6), 1437-1445. 